\title{
Efeitos Sociais e Econômicos para o Desenvolvimento Local através das contribuições do Programa Bolsa Família no município de Sinop- MT no período de 2004 a 2009
}

Social and Economic effects for local development through the contributions of the family allowance program in te city of Sinop-MT in te period 2004 to 2009

Effets économiques et sociaux pour le développement local grâce à la contribution du Programme d'allocations familiales dans la ville de Sinop-MT dans la période 2004 à 2009

Efectos socials y económicos para el Desarrollo local através de lãs contribuciones Del programa de Asignación Familiar em la ciudade de SinopMT em el período 2004 a 2009

\author{
João Germano Rosinke* \\ Cláudia Regina Heck** \\ Wylmor Constantino Tives Dalfovo*** \\ Aloisio Ruscheinsky****
}

Recebido em 22/3/2010; revisado e aprovado em 19/7/2010; aceito em 22/10/2010

\begin{abstract}
Resumo: O artigo busca identificar o perfil social e econômico dos beneficiados pelo programa bolsa família no município de Sinop-MT, no que diz respeito à quantidade de residentes por domicílio, à renda familiar e os gastos mensais, demonstrando o impacto que a renda do programa tem sobre a organização familiar e seu nível de bemestar. Busca também demonstrar o potencial econômico que o programa oferece à economia local, quanto à renda e uso do benefício no acesso ao crédito para maior conforto à população de baixa renda.

Palavras-chave: Renda. Redistribuição. Programa Bolsa Família.
\end{abstract}

Abstract: The article aims to identify the social and economic profile of beneficiaries of the Bolsa Familia program at Sinop-MT, with respect to the number of residents per household, family income and monthly expenditures, demonstrating the impact that the program has income on family organization and their level of wellness. It also seeks to demonstrate the economic potential offered by the program to the local economy, while income and use the benefit of access to credit for comfort to low-income population.

Key-words: Income. Redistribution. Bolsa Familia Program.

Résumé: L'article cherche identifier le profil social et économique des bénéficiées crée par le programme « bourse famille » dans la ville de Sinop-MT, en ce qui concerne ne nombre de personnes par ménage, le revenu et les dépenses par ménage, la démonstration de l'impact crée par le revenu du programme sur l'organisation familial et son niveau de bien-être. L'article cherche aussi démontrer le potentiel économique que le programme offre à l'économie local, par rapport au revenu et l'utilisation de l'aide à l'accès au crédit pour fournir plus de confort à la population de faible revenu.

Mots-clés: Revenu. Redistribution. Programme Bourse Famille.

Resumen: El artículo busca identificar el perfil social y económico de los beneficiados por el programa bolsa família en el município de Sinop-MT, en lo referente a la cantidad de residentes por domicilio, la renda familiar y los gastos mensuales, demostrando el impacto que la renda del programa tiene sobre la organización familiar y su nivel de bienestar. Busca tambien demostrar el potencial econômico que el programa ofrece a la economia local, cuando la renda y el uso del beneficio son usados en el acceso al crédito para mayor comodidad de la la población de baja renda. Palabras clave: Income. Redistribution. Program Bolsa Família.

\footnotetext{
* Economista, Professor do Departamento de Economia da Universidade do Estado de Mato Grosso, Campus Universitário de Sinop. Email: joão_rosinke@hotmail.com

** Economista, Mestre em Desenvolvimento, Professora do Departamento de Economia da Universidade do Estado de Mato Grosso, Campus Universitário de Sinop. Email: clauheck@hotmail.com

*** Economista, Mestre em Desenvolvimento, Professor do Departamento de Economia da Universidade do Estado de Mato Grosso, Campus Universitário de Sinop. Email: Wylmor.dalfovo@hotmail.com

**** Cientista Social, Professor do Programa de Mestrado em Ciências Sociais da Universidade do Vale do Rio dos Sinos - UNISINOS. Email: aloisior@unisinos.br
} 


\section{Introdução}

Ao crescimento econômico estão relacionadas as expectativas da sociedade, e a distribuição da renda de forma equilibrada traduz os anseios da maioria da população brasileira. Ao analisarmos historicamente as economias mundiais, vimos que grande parte dos países já enfrentaram ou enfrentam problemas para obter a equidade na distribuição da renda nacional.

A estabilidade econômica conquistada com o plano real e a garantia de direitos através da constituição de 1988, são fatores responsáveis por avanços na diminuição da pobreza e da evolução da renda entre os mais pobres, segundo dados apontados pela PNAD, conforme exposto pelo IBGE (2010). A dinâmica excludente do sistema capitalista faz milhões de famílias viverem na situação de miséria. No caso brasileiro esta situação é facilmente identificada em qualquer região periférica de quase todas suas cidades. Portanto através do Estado busca-se soluções para promover uma redução nas desigualdades sociais, entre estas está a redistribuição da renda através dos Programas de Garantia de Renda Mínima, entre estes, o Programa Bolsa Família que norteia o estudo a seguir.

O Programa Bolsa Família criado pelo Governo Federal como política de distribuição de renda tem sido responsável pelo auxílio a muitas famílias que estão abaixo da linha de pobreza, levando-os a participar do mercado de bens e serviços e melhorar a sua qualidade de vida. As condicionalidades impostas pelo programa visam garantir o resultado de longo prazo para a política.

O Município de Sinop-MT, apesar de apresentar uma economia dinâmica e em expansão possui um grande número de famílias beneficiárias, o que demonstra que o crescimento econômico não é condição única para o desenvolvimento social. É por estes motivos que o presente estudo visa analisar, por meio da temática que apresenta, o programa bolsa família no município de Sinop-MT, entre 2004-2009 e os impactos que este programa produz na economia do município.

\section{Visão geral sobre a renda e distribuição}

Historicamente, o sistema econômico se desenvolve à medida que as atividades de produção começam a gerar excedente. Inicialmente, as trocas permitiram à sociedade elevar o seu nível de consumo e satisfação, em função do aumento da disponibilidade de bens. Com o desenvolvimento da produção e das atividades de comércio, este excedente passou a representar a renda do agente econômico e determinar a sua capacidade de consumo. Desta forma, renda é denominada como fluxo de unidade monetária, por unidade de tempo, e representa o excedente de uma atividade econômica.

Blanchard (2001, p. 67) afirma que a "renda é o que você ganha - seja como remuneração do trabalho, renda de aluguéis ou de recebimento de juros ou dividendos". Complementando está ideia Gastaldi (2005, p. 344) destaca que

[...] a renda representa riquezas periódicas em dinheiro ou utilidades, provenientes de terras arrendadas ou imóveis alugados; explorações industriais ou comerciais; aplicação de capitais, títulos ou empréstimos; salários, vencimentos, ordenados, gratificações, etc.

Para Sen, (2000) o desenvolvimento deve ser visto como um processo de expansão das liberdades individuais. Essa liberdade pode ser política, econômica, oportunidades sociais, garantias de transparência e segurança protetora. Garantindo esses direitos chegar-se-ia a uma sociedade desenvolvida. Ainda, o autor afirma que a privação das capacidades individuais está fortemente ligada a um baixo nível de renda, porém, demonstra que somente a melhoria na renda não garante a liberdade individual.

De acordo com Furtado (2000, p. 155) se o aumento da produção "fosse sempre absorvido pelo consumo, melhorariam momentaneamente as condições de vida da população, sem que nenhuma alteração sofresse a capacidade produtiva". No entanto, forma-se na sociedade pequenos grupos que conseguem apropriar-se de excedente de produção, permanente ou ocasional, e este fato é a base do processo de desenvolvimento.

A partir da segunda metade do século XX, o Estado passa a ser mais participa- 
tivo seguindo os princípios das políticas Keynesianas e corrigindo as distorções do liberalismo econômico até então reinante nas principais economias mundiais. Para tanto, o Estado deve cumprir com algumas funções próprias de sua estrutura, dentre as quais merecem destaque neste artigo as funções alocativas e distributivas. De acordo com Musgrave (1974) a função alocativa que trata da provisão dos bens públicos (fornecimento de bens e serviços indispensáveis à sociedade) e a função distributiva que se refere à organização da distribuição renda.

Para Cruz e Pessali (2009), as funções econômicas do Estado e as políticas públicas vêm do reconhecimento das falhas do sistema de mercado quanto à satisfação social no que se refere à alocação de recursos eficiente e "justa", em seu caráter distributivo e visam compensar a exclusão gerada por mecanismos sócio-econômicos de alocação de recursos.

Os programas de redistribuição da renda no Brasil surgem no começo da década de 1990 e com o Plano Real se expandem. Por meio do controle inflacionário, de programas específicos de redistribuição da renda e também de reajustes salariais, que a partir de 2004 passam a ser corrigidos pela taxa de inflação mais a variação no PIB, verifica-se esforços em redistribuir renda no Brasil. Segundo Lavinas (1997) para ampliar os efeitos de longo prazo destes programas de redistribuição de renda eles vinculam o beneficio a frequência escolar e cuidados com a saúde reduzindo a probabilidade de reprodução da pobreza em gerações futuras.

Estudos realizados pelo Instituto de Pesquisa Econômica Aplicada - IPEA demonstram que a desigualdade de renda apresenta declínio acentuado no país desde 2001. De acordo com Medeiros et al. (2007), em 2005, o gasto total com as transferências de renda no Brasil por meio do Beneficio de Prestação Continuada - BPC, salientando-se que o BPC é um programa de transferência de renda mensal a pessoas com deficiência severa, de qualquer idade, e idosos maiores de 65 anos, em ambos os casos com renda familiar per capita inferior a um quarto de salário mínimo e do Programa Bolsa Família que foi de aproximadamente $0,8 \%$ do PIB, beneficiando treze milhões de famílias de baixa renda. Ainda para Medeiros et al. (2007, p.
24)“ estes programas estão cumprindo, em boa medida, seus propósitos e sendo efetivamente direcionados para a população mais pobre". Apesar da recente queda a desigualdade no país continua elevada, segundo o PNUD (2010) a desigualdade de renda é a que mais pesa sobre o IDH-D brasileiro.

No entanto, desde a sua concepção esses projetos recebem inúmeras críticas. Segundo Lavinas (1997) um dos objetivos dos Programas de Garantia de Renda Mínima é proporcionar condições dignas à população carente, no que se inclui segurança pública, defesa civil, além de acesso à saúde e educação, e essas condições não são atendidas em sua integralidade. Além de criticas de que as transferências desestimulam o beneficiário ao trabalho e a instabilidade quanto à oferta do beneficio a sociedade.

Segundo Medeiros et al. (2007) não há evidências empíricas que as transferências desestimulem ao trabalho, uma vez que

[...] dados do IBGE mostram que pessoas que vivem em domicílios onde há beneficiários do Bolsa Família trabalham tanto ou mais que outras pessoas com renda familiar per capita similar.

A seguir apresenta-se o Programa Bolsa Família, enquanto Programa de Garantia de Renda Mínima do Governo brasileiro e os resultados econômicos obtidos através do Programa no Município de Sinop-MT. Apesar de permear as discussões sociais, este artigo não pretende se aprofundar nos aspectos sociais, mas sim nos benefícios econômicos para os beneficiários do Programa e para a sociedade.

\section{Programa de Garantia de Renda Mínima - Bolsa Família}

Atualmente, o principal programa de redistribuição da renda no Brasil é o Programa Bolsa Família, que foi criado no ano de 2003 e formalizado com a Lei n. 10.836, de 09 de janeiro de 2004, e regulamentado pelo Decreto no 5.209, de 17 de setembro de 2004. É um programa social do Governo Federal que está vinculado ao Ministério do Desenvolvimento Social e Combate a Fome (MDS), de transferência direta de renda e que em contra partida exige o cumprimento de condicionalidades por parte das famílias integrantes do programa. 
De acordo com Weissheimer (2006, p. 36), o programa foi criado a partir de

[...] programas sociais de transferência de renda espalhado por vários ministérios, com diferentes listas de beneficiários e critérios para recebimentos de benefícios. Esse sistema "espalhado" foi submetido a um processo de unificação, decisão que exigiu, entre outras coisas, o recadastramento e a unificação dessas listas e a redefinição de critérios.

O objetivo é beneficiar famílias em situação de pobreza que possuem renda mensal por pessoa de até $R \$ 140,00$ e que estejam devidamente cadastradas no Cadastro Único. Este cadastro é de responsabilidade das prefeituras municipais, e seu preenchimento não implica que o benefício seja pago automaticamente, o Ministério que irá fazer de forma automatizada a liberação do benefício. Segundo o Ministério do Desenvolvimento Social e Combate a Fome (MDS, 2009), a preocupação do programa está centrada em três dimensões:
- Promoção do alívio imediato da pobreza, por meio da transferência direta de renda à família;

- Reforço ao exercício de direitos sociais básicos nas áreas de Saúde e Educação, por meio do cumprimento das condicionalidades;

- Coordenação de programas complementares, que têm por objetivo o desenvolvimento das famílias, de modo que os beneficiários do programa consigam superar a situação de vulnerabilidade e pobreza.

Os valores pagos pelo Programa Bolsa Família variam de $\mathrm{R} \$ 22,00$ a $\mathrm{R} \$ 200,00$ de acordo com a renda mensal por pessoa da família e com o número de crianças e adolescentes de até 15 anos e de jovens de 16 e 17 anos. Para que haja um melhor entendimento dos valores repassados às famílias serão apresentadas duas tabelas de cálculo de benefício do Programa Bolsa Família, a primeira é aplicada para famílias com renda familiar de até $\mathrm{R} \$ 70,00$.

Tabela 1 - Formação dos Benefícios do PBF.

\begin{tabular}{cclc}
\hline $\begin{array}{c}\text { Número de crianças } \\
\text { e adolescentes de até } \\
\mathbf{1 5} \text { anos }\end{array}$ & $\begin{array}{c}\text { Número de jovens de } \\
\mathbf{1 6} \text { e } \mathbf{1 7} \text { anos }\end{array}$ & \multicolumn{1}{c}{ Tipo de benefício } & Valor do benefício \\
\hline 0 & 0 & Básico & 68,00 \\
\hline 1 & 0 & Básico+1 variável & 90,00 \\
\hline 2 & 0 & Básico+2 variáveis & 112,00 \\
\hline 3 & 0 & Básico+3 variáveis & 134,00 \\
\hline 0 & 1 & Básico+1 BVJ* & 101,00 \\
\hline 1 & 1 & Básico+1 variável+1 BVJ & 123,00 \\
\hline 2 & 1 & Básico+2 variáveis+1 BVJ & 145,00 \\
\hline 3 & 1 & Básico+3 variáveis+1 BVJ & 167,00 \\
\hline 0 & 2 & Básico+2 BVJ & 134,00 \\
\hline 1 & 2 & Básico+1 variável+2 BVJ & 156,00 \\
\hline 2 & 2 & Básico+2 variáveis+2 BVJ & 178,00 \\
\hline 3 & 2 & Básico+3 variáveis+2 BVJ & 200,00 \\
\hline
\end{tabular}

Fonte: Ministério do Desenvolvimento Social e Combate a Fome (2009).

Nota: *Benefício Variável por Jovem.

Para aquelas famílias cuja renda mensal por integrante não passe de $\mathrm{R} \$ 70,00$ é pago o benefício básico no valor de $\mathrm{R} \$ 68,00$ mesmo que elas não tenham crianças, adolescentes ou jovens. Além do valor básico poderá completar a renda tendo um acréscimo por criança ou adolescente de até 15 anos e/ou jovem entre 16 e 17 anos, que cumpram as condicionalidades, podendo chegar até o valor de $\mathrm{R} \$ 200,00$. A seguir a tabela de cálculo para as famílias que possuem renda mensal por integrante de até $\mathrm{R} \$ 140,00$. 
Tabela 2 - Formação dos Benefícios do PBF.

\begin{tabular}{cclc}
\hline $\begin{array}{c}\text { Número de crianças e } \\
\text { adolescentes de até } \mathbf{1 5} \\
\text { anos }\end{array}$ & $\begin{array}{c}\text { Número de jovens } \\
\text { de 16 e 17 anos }\end{array}$ & \multicolumn{1}{c}{ Tipo de benefício } & $\begin{array}{c}\text { Valor do } \\
\text { benefício }\end{array}$ \\
\hline 0 & 0 & Não recebe benefício básico & - \\
\hline 1 & 0 & 1 variável & 22,00 \\
\hline 2 & 0 & 2 variáveis & 44,00 \\
\hline 3 & 0 & 3 variáveis & 66,00 \\
\hline 0 & 1 & 1 BVJ* & 33,00 \\
\hline 1 & 1 & 1 variável + 1 BVJ & 55,00 \\
\hline 2 & 1 & 2 variáveis + 1 BVJ & 77,00 \\
\hline 3 & 1 & 3 variáveis + 1 BVJ & 99,00 \\
\hline 0 & 2 & 2 BVJ & 66,00 \\
\hline 1 & 2 & 1 variável + 2 BVJ & 88,00 \\
\hline 2 & 2 & 2 variáveis + 2 BVJ & 110,00 \\
\hline 3 & 2 & 3 variáveis + 2 BVJ & 132,00 \\
\hline
\end{tabular}

Fonte: Ministério do Desenvolvimento Social e Combate a Fome (2009).

*Benefício Variável por Jovem.

Nesta parcela de beneficiários somente recebem benefícios as famílias que possuem crianças e adolescentes de até 15 anos e/ou jovens entre 16 a 17 anos que cumpram as condicionalidades impostas pelo programa. Podendo neste caso receber até três benefícios variáveis que poderá somar valores entre $\mathrm{R} \$$ 22,00 a $\mathrm{R} \$ 132,00$.

As condicionalidades do Programa Bolsa Família dividem-se em três setores: na educação é exigida frequência mínima de $85 \%$ para crianças e adolescentes e $75 \%$ para jovens entre 16 e 17 anos. Na saúde está o acompanhamento do calendário vacinal e do crescimento e desenvolvimento para crianças menores de sete anos; e pré-natal das gestantes e acompanhamento das gestantes na faixa etária de 14 a 44 anos. Por fim quanto à assistência social é exigida frequência mínima de $85 \%$ da carga horária relativa aos serviços sócios educativos para crianças e adolescentes de até 15 anos em risco ou retiradas do trabalho infantil.

Desde o início da vigência do PBF pode-se notar um aumento nos totais de recursos destinados ao programa. Isto ocorre devido ao planejamento das políticas macroeconômicas da gestão do atual governo, que busca a diminuição da miséria e a segurança alimentar das famílias brasileiras. Além disto, o PBF passou por alguns reajustes nos valores transferidos e aumentou a margem da renda por integrante familiar para que se possa receber o beneficio, que no ano de 2006 era de no máximo $R \$ 120,00$, atualmente é de $R \$$
140,00; fazendo com que o total repassado no último semestre de 2008 chegasse a mais de 5 bilhões de reais.

De acordo com o Jornal The Economist apud Weissheimer (2006, p. 50) o volume de recurso empregado é relativamente modesto:

[...] o Bolsa Família do Brasil custa ao governo federal $0,36 \%$ do PIB, muito menos do que o sistema de previdência social. A transferência não se limita a dar dinheiro para os pobres, mas também serve como incentivo ao uso dos serviços governamentais.

No Estado de Mato Grosso o Programa Bolsa Família, segundo o Ministério de Desenvolvimento Social e Combate a Fome, em relatório divulgado no mês de Julho de 2009 atende a 142,2 mil famílias somando R \$11,4 milhões repassados a cada mês. Recursos que abrangem 469 mil pessoas e que por ano acrescenta R\$136,8 milhões na economia estadual.

\subsection{O Programa Bolsa Família no município de Sinop-MT}

A cidade de Sinop está situada na região norte do Estado de Mato Grosso e sua emancipação política ocorreu no ano de 1979. Atualmente, conta com uma população estimada em 105 mil habitantes distribuída em uma área total de $3.985,52 \mathrm{~km}^{2}$, sendo o comércio e a prestação de serviços as principais atividades econômicas. O Produto Interno Bruto a preço de mercado (PIBpm) de cerca de R\$ 1,09 bilhões por ano e um PIB per capita de R\$ 10.565,00 (IBGE, 2009). 
O Programa Bolsa Família beneficiou no mês de Julho de 2009, 1.638 famílias no município, conforme dados do MDS, correspondente a $1,56 \%$ de sua população. Este percentual é relativamente reduzido quando comparado com outros municípios do Estado. No município de Cáceres, por exemplo, que possui população de 86.805 habitantes no ano de 2006, e com PIB a preço de mercado de $\mathrm{R} \$$ 616,8 milhões e renda per capita de $\mathrm{R} \$ 7.106,00$ por ano (IBGE, 2009), o número de beneficiários atinge um total de 4.935 famílias; que correspondem a $5,69 \%$ da população total. Desta forma, pode-se concluir que o município de Sinop, que representa a quarta maior receita orçamentária do Estado (SEPLAN, 2009) e possui uma renda per capita superior à média estadual, apresenta uma demanda menor por programas sociais, como o Bolsa Família.

A gestão e a fiscalização do programa ocorrem através do Conselho Municipal, formados por representantes do poder público e da sociedade civil organizada. Uma vez feito o cadastro, o beneficiário do Programa só deixa de receber o beneficio se descumprir as condicionalidades - frequência escolar e acompanhamento da saúde - ou se for denunciado e receber a visita dos conselheiros municipais. Isso faz com que algumas pessoas, mesmo tendo mudado sua condição de renda, possam permanecer no programa.

Estudo realizado no segundo semestre de 2009, com uma amostragem aleatória simples de 57 famílias beneficiadas, buscou identificar as características das famílias beneficiadas no Município de Sinop-MT. A investigação abrange um total de 277 pessoas sendo 133 menores cadastrados no programa.

Em média a entrevista apontou a composição dos domicílios com 4,8 pessoas, sendo 2,3 menores cadastrados para cada lar. Segundo os dados divulgados pela Pesquisa Nacional por Amostra de Domicílios - PNAD (2007), a composição média familiar no Brasil encontra-se em 3,2 pessoas por domicilio particular. Já na região Centro-Oeste esse número é de 3,1 pessoas em cada residência. A composição de domicílios cujas famílias encontram-se em situações de pobreza e miséria é superior à media nacional. A seguir apresentam-se dados coletados pela pesquisa no que se refere à aplicação da renda, a situação do domicílio e a participação no programa:

Tabela 3 - Tempo de participação no PBF, condição de ocupação do domicilio e despesas mensais com habitação, água e energia dos beneficiários.

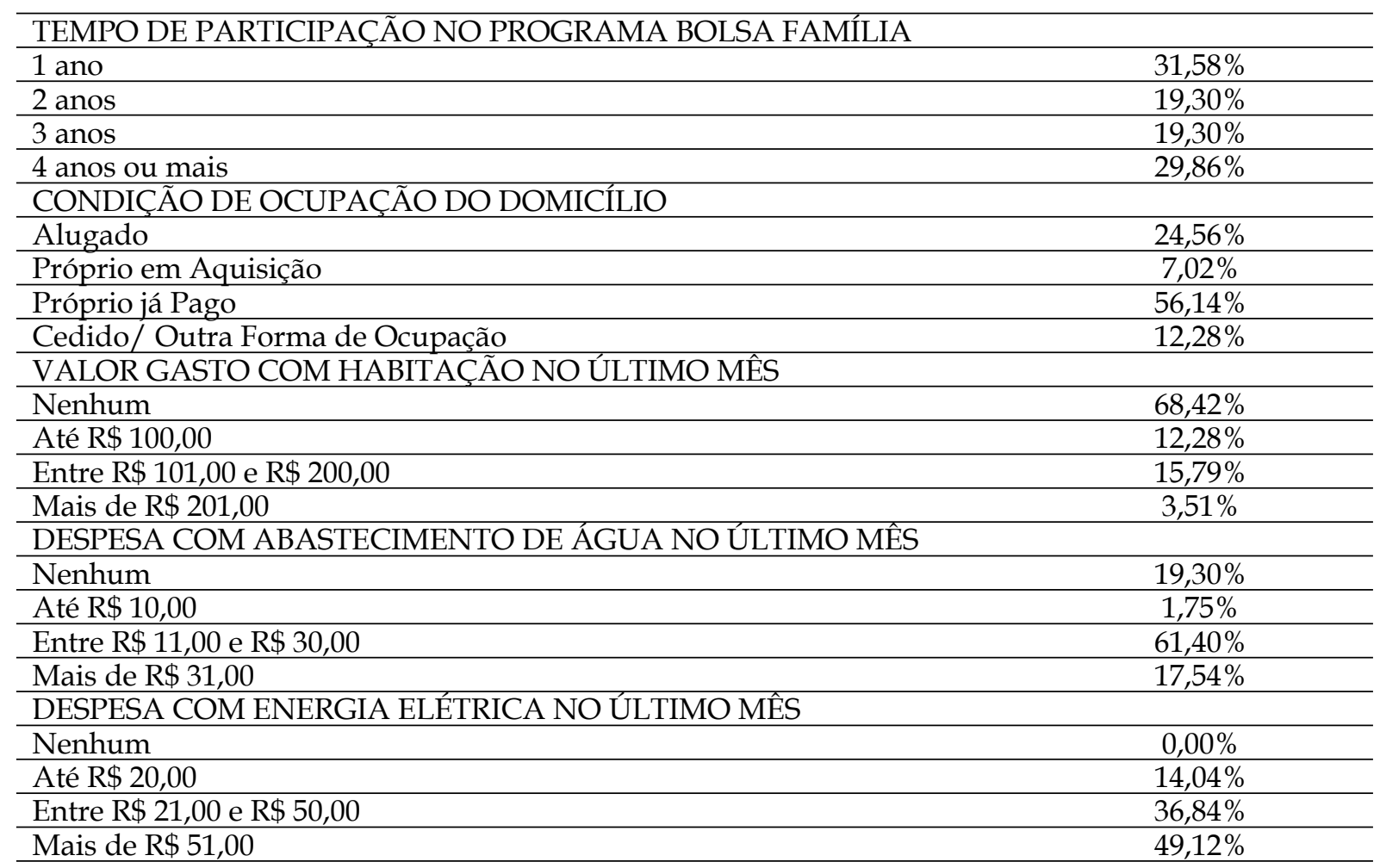

Fonte: Pesquisa de Campo (2009). 
Observa-se na tabela acima, que a maior parte das famílias entrevistadas está no seu primeiro ano de participação no PBF. A frequente atualização do cadastro único por parte do município e a análise dos dados pelo MDS aponta que famílias que antes necessitavam do auxílio do programa não têm mais o perfil que o programa exige. Principalmente na renda per capita da família. Por este fato, ocorre a renovação do cadastro apontada pela pesquisa. Outro fator que tem influência direta, porém com participação menos significante na renovação dos cadastros, é o acompanhamento das condicionalidades. Cada vez que uma família não cumpre com as condições impostas pelo programa, e esta é observada pelo órgão responsável, a família recebe uma advertência. Se continuar descumprindo as condicionalidades pode ter o beneficio bloqueado e persistindo na situação terá o beneficio cancelado.

Pela localização das moradias das famílias entrevistadas estarem situadas em regiões periféricas da cidade de Sinop, a pesquisa constatou que mais de $50 \%$ dos entrevistados responderam que residem em casa própria totalmente paga. Somente $12,28 \%$ das famílias afirmam morar em imóvel cedido e $24,56 \%$ dos entrevistados diz morar em imóvel alugado. Neste sentido, o estudo traz um resultado importante, pois à medida que a família não tem gastos com habitação ela dispõe desta renda para o gasto com seu bem-estar, principalmente como veremos a seguir para o gasto com alimentação.

Outro indicador de qualidade de vida é a presença de água tratada nas residências. O estudo verificou esta situação e mensurou os gastos das famílias com o abastecimento de água no domicilio. Mais de $60 \%$ das famílias entrevistadas apresenta gastos com abastecimento de água que variam entre $\mathrm{R} \$$ 11,00 e R \$ 30,00 por mês. Isto ocorre pelo fato de a tarifa básica exercida pelo Serviço Autônomo de Água e Esgoto de Sinop para quem consome até $15 \mathrm{~m}^{3}$ de água por mês é de $\mathrm{R} \$ 14,30$. Também nota-se que cerca de $20 \%$ dos entrevistados não possuem gastos com abastecimento de água devido principalmente à presença de poços semi-artesianos em suas residências, o que não significa menos gastos, pois a presença destes poços requer bomba de sucção que consome energia, aumentando o valor mensal desprendido para o pagamento da conta de energia elétrica.

A despesa com energia elétrica possui um peso significativo no orçamento familiar, ainda maior em famílias com renda baixa como as atendidas pelo PBF, aponta-se a seguir os gastos mensais com energia elétrica. Através da tabela acima se verifica que todas as famílias entrevistadas possuem gastos com energia elétrica. Sabe-se que esta é uma condição que proporciona conforto para as famílias e acaba onerando o orçamento familiar. Para 49,12\%, quase a metade dos entrevistados, o dispêndio com energia ultrapassa o valor de $\mathrm{R} \$ 51,00$. Considerando uma família com renda de $\mathrm{R} \$ 465,00$ a energia elétrica representa $10,97 \%$ da renda total.

Somando-se as despesas fixas mensais, de acordo com os dados da pesquisa, podemos projetar que uma família com renda de um salário mínimo e que gasta mensalmente cerca de $R$ \$100,00 em aluguel; $R$ \$ 14,30 em água e $\mathrm{R} \$ 51,00$ em energia elétrica, ela tem comprometida $35,48 \%$ da sua renda total em gastos fixos mensais. Restando aproximadamente $\mathrm{R} \$$ 300,00 para o consumo. Como a maioria não possui a despesa com aluguel, as despesas mensais com água e energia comprometem $14,04 \%$ do orçamento familiar.

A análise da renda das famílias beneficiadas é importante para o presente estudo, pois é condição principal para o ingresso no programa do governo. Desta forma, buscou-se identificar a renda total das famílias sem o benefício e qual o valor recebido através do $\mathrm{PBF}$, sendo que o resultado se apresenta da seguinte forma: 
Tabela 4 - Renda Familiar e Valor Recebido Através do PBF pelo Número de Famílias.

\begin{tabular}{|c|c|c|c|c|c|}
\hline $\begin{array}{c}\text { Renda/Valor do } \\
\text { Benefício }\end{array}$ & $\begin{array}{l}\text { Até R\$ } \\
300,00\end{array}$ & $\begin{array}{c}\text { Entre } R \$ 301,00 \\
\text { e } 465,00\end{array}$ & $\begin{array}{c}\text { Entre } R \$ 466,00 \\
\text { e } 600,00\end{array}$ & $\begin{array}{l}\text { Acima de } \\
R \$ 601,00\end{array}$ & $\begin{array}{c}\text { Total } \\
\text { recebido }\end{array}$ \\
\hline $\mathrm{R} \$ 22,00$ & 1 & - & 2 & 2 & 110,00 \\
\hline $\mathrm{R} \$ 33,00$ & - & 1 & - & 1 & 66,00 \\
\hline $\mathrm{R} \$ 44,00$ & - & 5 & 4 & - & 396,00 \\
\hline $\mathrm{R} \$ 55,00$ & 1 & 2 & 1 & 1 & 275,00 \\
\hline $\mathrm{R} \$ 66,00$ & 1 & 3 & 4 & 2 & 660,00 \\
\hline $\mathrm{R} \$ 68,00$ & 1 & 4 & 3 & - & 544,00 \\
\hline $\mathrm{R} \$ 77,00$ & - & - & - & 1 & 77,00 \\
\hline $\mathrm{R} \$ 88,00$ & - & 2 & 1 & 1 & 352,00 \\
\hline $\mathrm{R} \$ 90,00$ & 3 & 2 & 1 & - & 540,00 \\
\hline $\mathrm{R} \$ 101,00$ & 1 & - & - & - & 101,00 \\
\hline $\mathrm{R} \$ 110,00$ & 1 & - & - & - & 110,00 \\
\hline $\mathrm{R} \$ 112,00$ & 3 & - & - & - & 336,00 \\
\hline $\mathrm{R} \$ 123,00$ & 1 & - & - & - & 123,00 \\
\hline $\mathrm{R} \$ 132,00$ & - & - & 1 & - & 132,00 \\
\hline TOTAL & 13 & 19 & 17 & 8 & $3.822,00$ \\
\hline
\end{tabular}

Fonte: Pesquisa de Campo (2009).

Consegue-se identificar a faixa de renda de cada uma das famílias entrevistadas. Nota-se que 22,8\% das famílias entrevistadas vivem em seus domicílios com renda média na faixa até $\mathrm{R} \$ 300,00$ e o valor recebido por $70 \%$ dessas famílias ultrapassa o valor de $\mathrm{R} \$$ 90,00 mensais, o que comprova a necessidade de estarem participando do PBF. De outro lado, $68,2 \%$ das famílias recebem benefício de $R \$ 22,00$ a $R \$ 68,00$ mensais, sendo que a maioria destas possui renda superior a $\mathrm{R} \$$ 301,00. Isto se dá em função de que os benefícios abaixo de $\mathrm{R} \$ 68,00$ são pagos a famílias com renda per capita de até $R \$ 140,00$ e que possuem menores dependentes.

Por meio da identificação do número de famílias, da renda familiar de cada uma delas e do valor do benefício de cada entrevistado pode-se calcular o valor total recebido pelas famílias entrevistadas. Constata-se que as 57 famílias recebem a soma de $\mathrm{R} \$ 3.822,00$ mensais, sendo o valor médio pago pelo programa entre as famílias entrevistadas é de $\mathrm{R} \$ 67,05$.

Cabe ressaltar que a média fica estabelecida abaixo do mínimo fixo repassado pelo programa em função do grande número de famílias com renda per capita de até $\mathrm{R} \$$ 140,00 mensais que recebem somente o valor variável por dependente. Considerando que o município de Sinop possui um total de 1.638 beneficiados, no mês de Julho de 2009, estima-se que o montante médio de recursos repassados pelo PBF é de $R \$ 109.827,90$ por mês e R $\$ 1.317 .934,80$ por ano. Se todas as famílias receberem o valor mínimo pago pelo programa de $R \$ 22,00$ o total repassado por ano seria de $\mathrm{R} \$ 432.432,00$ em transferência direta de recursos para a economia local.

No que se refere à aplicação do recurso recebido pelas famílias, através do Programa Bolsa Família, verifica-se que todo o recurso é gasto na economia local e que beneficia exclusivamente os comerciantes e prestadores de serviços do município. Neste sentido o estudo aponta que $100 \%$ das pessoas entrevistadas afirmam gastar a renda no município. Este montante é distribuído nas seguintes áreas:

Tabela 5 - Como é Gasta a Renda Recebida do Programa Bolsa-Família.

\begin{tabular}{lc}
\hline \multicolumn{1}{c}{ Item } & $\%$ \\
\hline Alimentação & 68,42 \\
\hline Saúde & 7,02 \\
\hline Educação & 14,04 \\
\hline Lazer & 3,51 \\
\hline Outra Forma & 7,02 \\
\hline
\end{tabular}

Fonte: Pesquisa de Campo (2009).

Dos entrevistados $68,42 \%$ afirmam gastar a renda recebida através do PBF com a alimentação das pessoas residentes no domicilio. Um dos objetivos do PBF é a segurança alimentar destas famílias, para que se consiga um bom desempenho escolar e um desenvolvimento da saúde das crianças adequado. Este gasto da renda com a alimentação aponta que os objetivos do programa estão sendo alcançados. Com a educação, afirmam gastar 
a renda do programa $14,04 \%$ das famílias. Em seguida, aparecem os gastos em saúde com $7,02 \%$ e lazer com 3,51\%; com outra forma não disponibilizada no questionário 7,02\% dos entrevistados dizem gastar o benefício.

Diante das informações apresentadas, buscou-se identificar a opinião das famílias atendidas pelo PBF quanto à satisfação com o programa do governo federal. Constatou-se que $54,39 \%$ dos entrevistados consideram o programa bom, $36,84 \%$ consideram o programa ótimo e apenas $8,77 \%$ consideram o programa regular. È esperado que, por ser uma redistribuição de maneira direta em moeda, que o programa tivesse esta avaliação. Por fim, nenhum dos entrevistados afirmou que o PBF é um programa ruim. Isto pode ser explicado pelo impacto que a renda transferida pelo governo federal provoca no orçamento familiar.

Verificou-se também, se a renda redistribuída pelo Estado melhora ou não a situação financeira familiar, 54,39\% dos entrevistados disseram que a sua situação financeira melhorou após ingressarem no PBF, 26,32\% afirmam que é muito melhor a sua situação financeira após o programa e 19,30\% dizem que a situação financeira de sua família con- tinua a mesma após a participação no PBF. É evidente que a transferência de um recurso de forma direta impacta na situação financeira de uma família. Porém, deve-se ter o cuidado de identificar que estas famílias continuam auferindo os proventos com seu trabalho antes e após participarem do programa.

Segundo informações do Ministério do trabalho e Emprego entre os meses de janeiro e julho de 2009 foram criados 543 postos de trabalho no município, um acréscimo de $2,58 \%$ no número de vagas. As informações do cadastro único do PBF são atualizadas anualmente e são fiscalizadas pelos conselhos municipais, pela confrontação da RAIZ. Portanto uma família pode continuar recebendo auxílio do programa mesmo com renda incompatível com a exigida para a participação no programa pelo período de até um ano.

Além da satisfação das necessidades básicas a pesquisa buscou-se identificar outras melhorias proporcionadas pela participação no programa. Desta forma, foram perguntadas principalmente por equipamentos eletrodomésticos que a casa possui e se teria sido adquirido antes ou depois da participação no programa. A seguir tem-se a análise:

Tabela 6 - Itens Presentes no Domicílio.

\begin{tabular}{lccc}
\hline \multirow{2}{*}{ DESCRIÇÃO } & \multicolumn{3}{c}{ POSSUI } \\
\cline { 2 - 3 } & ANTES & SIM & NEP̃O \\
\cline { 2 - 3 } & $89,4 \%$ & $3,5 \%$ & $7,10 \%$ \\
\hline Fogão a gás & $0 \%$ & $3,5 \%$ & $96,5 \%$ \\
\hline Freezer & $94,7 \%$ & $5,3 \%$ & $0,00 \%$ \\
\hline Geladeira & $1,7 \%$ & $3,5 \%$ & $94,7 \%$ \\
\hline Microondas & $22,8 \%$ & $26,3 \%$ & $50,9 \%$ \\
\hline Liquidificador & $19,3 \%$ & $10,5 \%$ & $70,2 \%$ \\
\hline Ferro elétrico & $57,8 \%$ & $22,8 \%$ & $19,4 \%$ \\
\hline Maquina de lavar & $89,4 \%$ & $3,5 \%$ & $7,00 \%$ \\
\hline Televisão & $26,3 \%$ & $19,3 \%$ & $54,4 \%$ \\
\hline Rádio & $7,0 \%$ & $1,8 \%$ & $91,2 \%$ \\
\hline Aparelho de som & $7,0 \%$ & $26,3 \%$ & $66,7 \%$ \\
\hline Aparelho de DVD & $33,3 \%$ & $31,6 \%$ & $35,1 \%$ \\
\hline Ventilador & $1,7 \%$ & $1,8 \%$ & $96,5 \%$ \\
\hline Chuveiro elétrico & $0 \%$ & $3,5 \%$ & $96,5 \%$ \\
\hline Micro computador & $68,4 \%$ & $12,3 \%$ & $19,3 \%$ \\
\hline Bicicleta & $8,7 \%$ & $5,3 \%$ & $86,0 \%$ \\
\hline Motocicleta & $3,5 \%$ & $3,5 \%$ & $93,0 \%$ \\
\hline Automóvel & $28,0 \%$ & $50,9 \%$ & $21,1 \%$ \\
\hline Celular & & & \\
\hline
\end{tabular}

Fonte: Pesquisa de Campo (2009). 
Pode-se notar que eletrodomésticos de uso indispensável para as famílias estão presentes na maioria dos lares entrevistados, como é o caso da geladeira, do fogão a gás e da máquina de lavar. Também que sua aquisição em grande parte ocorreu antes da participação no programa devido ao alto grau de essencialidade que ele possui. No item fogão a gás ele está presente em $92,98 \%$ dos lares entrevistados. A máquina de lavar está em $80,70 \%$ das casas e a geladeira encontra-se em todas as residências abrangidas pela pesquisa.

$O$ ventilador por ser se uso essencial em períodos quentes e por ter preço relativamente baixo está presente em $64,91 \%$ das residências. Já os eletrodomésticos que não possuem uso essencial como liquidificador $(49,12 \%)$ e ferro elétrico $(29,82 \%)$, estão presentes em menos da metade das residências. Dentre os itens que menos constaram nas residências dos entrevistados estão o freezer e o chuveiro elétrico, aparecendo somente em 3,51\% das residências, por se tratarem de equipamentos de alto consumo de energia elétrica e por não serem de uso essencial. $\mathrm{O}$ micro-ondas aparece presente em 5,26\% das residências.

Dentre os eletroeletrônicos, a televisão, segundo os entrevistados, está em 92,98\% das casas abrangidas pela pesquisa, $45,61 \%$ possuem rádios, e 33,33\% aparelhos de DVD. Dentre os itens avaliados o aparelho de telefone celular é o que merece destaque e maior atenção, estando presente em 78,95\% das residências pesquisadas. Este constitui um novo gasto no orçamento familiar, porém muito difícil de mensurar, pois se trata de linhas pré-pagas e que não requerem gastos fixos mensais de seus usuários. Ainda, 80,70\% dos entrevistados afirmaram ter bicicleta, $14,04 \%$ possuir motocicleta e $7,02 \%$ ter automóveis. $\mathrm{O}$ micro-computador e o aparelho de som estão em menos de $10 \%$ das casas.

Quando se analisa os objetos que foram adquiridos com maior frequência após a participação da família no programa, vê-se que o freezer com $100 \%$, o microondas com $66,66 \%$, o aparelho de DVD com 78,94\%, o microcomputador com $100 \%$ e o telefone celular com $64,44 \%$ foram os itens com maior aquisição. Estes equipamentos têm sua essencialidade menor, por isto são comprados visando proporcionar maior conforto para a família.
Ocorre que ao participar do programa estas famílias passam a ter uma renda fixa mensal, que é aceita pelo comércio local como forma de comprovação de renda, que antes não existia, pois a maioria destas pessoas atua no mercado informal. Então passam a ter acesso ao crédito, conseguindo adquirirem eletrodomésticos e eletroeletrônicos, os quais não tinham acesso.

\subsection{Impacto do Programa Bolsa Família sobre a atividade de Comércio em Sinop/MT}

Para a economia do Município de Sinop, o setor de comércio é responsável pela geração de grande número de empregos, distribuição de renda e influência no tempo de circulação do dinheiro na economia. Desta forma, torna-se importante, do ponto de vista econômico, identificar o impacto que o programa tem sobre o desenvolvimento do comércio local, uma vez que, conforme visto anteriormente, o volume médio de recursos transferidos anualmente pelo Programa é elevado.

Segundo Secretária de Estado de Planejamento (2007) o setor do comércio corresponde a $46,2 \%$ da economia do município. Nas três últimas décadas Sinop, tornou-se a cidade pólo da região norte do Estado de Mato Grosso, influenciando o desenvolvimento dos municípios próximos. Tornou-se grande fornecedora de mercadorias e serviços principalmente voltada ao fomento da atividade extrativista da madeira no princípio, e nos dias atuais atua no suporte a atividade agrícola.

De acordo com o Senso Econômico desenvolvido pelo Governo do Estado (SEPLAN, 2007), o setor de comércio destacou-se na geração de postos de trabalho no município com $44,4 \%$ do total das vagas, seguido pelos serviços com $42,3 \%$ e a indústria com $13,3 \%$.

Para avaliar o impacto do PBF na economia local realizou-se estudo qualitativo no comércio do Município de Sinop, no segundo semestre de 2009, através de entrevistas com gerentes e proprietários de alguns estabelecimentos comerciais mais citados pelas famílias que recebem o benefício. O objetivo principal é a comprovação sobre o uso do benefício 
como forma de comprovação de renda para o acesso ao crédito no comércio local; e para isto foram entrevistadas três empresas do ramo de alimentos e uma empresa do segmento de eletrodomésticos.

As empresas entrevistadas estão a mais de oito anos no comércio local, portanto trata-se de empresas consolidadas na economia de Sinop e que observaram a implementação do PBF no ano de 2004. Tem-se ainda uma empresa que está no município desde a sua fundação há 32 anos, que acompanhou todo o processo de crescimento da cidade e de sua economia.

Quando questionadas as empresas sobre a identificação da clientela que participa do $\mathrm{PBF}, 75 \%$ das empresas afirmam não ser possível identificar os clientes que recebem o auxílio, devido ao grande volume de clientes que compram nestas lojas e pela frequência com que estas compras ocorrem, ainda por se tratar de $75 \%$ das empresas do ramo de alimentos, não é possível identificar as famílias.

Verificou-se que todos comerciantes perceberam um incremento nas vendas após a implantação do PBF, que teve início em 2004, fato já comprovado por estudos de redução da pobreza. Das empresas entrevistadas, 25\% afirmaram identificar os produtos demandados pelos integrantes do programa, que por ser do ramo alimentício afirma que entre os produtos mais consumidos estão o arroz, feijão, farinha de trigo e alguns tipos de carne. Alimentos básicos na mesa de todas as famílias brasileiras, que o programa assegurou através do repasse de recursos diretamente para os atendidos pelo programa bolsa família.

Em relação à venda a crédito destaca-se entre os entrevistados a modalidade de cheque pré-datado presente em todos os estabelecimentos pesquisados. Pelo rápido e eficiente sistema de consulta de cheques e informações do cliente este tipo de venda segue entre as que estão mais presentes nos estabelecimentos comerciais. O convênio entre comércios, o carnê e o cartão de crédito estão em $50 \%$ dos estabelecimentos comerciais pesquisados, destacando-se o cartão como forma de pagamento posterior à compra, em grande ascensão no município. Por fim o cartão próprio onde a empresa fomenta a venda como maneira de atrair o cliente e obter lucro que antes ficaria para a operadora do cartão, esta modalidade está presente em $25 \%$ das empresas entrevistadas.

Um elemento importante é que todos os estabelecimentos entrevistados aceitam o cadastro no PBF como maneira para se comprovar a renda, seja como complemento de outra renda, seja como comprovação de forma integral da renda familiar. É visto que a competitividade entre o comércio e a disputa pela manutenção e arrecadação de novos clientes está por vez muito acirrada. Por outro lado, a comprovação da renda é fator determinante para que se consiga o parcelamento da compra de produtos que proporcionam incremento no bem-estar das famílias e que possuem muitas vezes um valor adicionado maior, que não estaria adequado ao orçamento familiar, se não fossem adquiridos de maneira parcelada. Desta forma, observa-se que o programa contribui para a economia local não somente pela transferência direta de recursos, mas também pelo aumento do crédito das famílias.

\section{Considerações Finais}

Políticas públicas de redistribuição da renda auxiliam no desenvolvimento econômico e social do país. Conforme demonstrado no referencial teórico essas ações auxiliam a economia em períodos de crise e servem como ferramentas para a manutenção do nível de consumo. Para a economia de alguns municípios, o Programa Bolsa Família significa uma parcela importante da economia local.

Este estudo permitiu a visualização dos resultados obtidos com o Programa Bolsa Família no Município de Sinop-MT, tanto para as famílias beneficiadas quanto para a economia do município como um todo. Também ressaltou a importância do programa como política de enfrentamento à pobreza ao verificar a situação financeira das famílias atendidas e a importância comprovada na complementação da renda desprendida com a alimentação das pessoas cadastradas no programa. Portanto, constata-se que os recursos destinados à população de baixa renda, por meio do Programa Bolsa Família, contribuem para o desenvolvimento da economia local e para o bem-estar das famílias atendidas. Destacam-se os resultados comprobatórios 
de que o Programa melhora, mesmo que temporariamente, a renda das famílias assistidas. Pois esta renda complementa o orçamento familiar, contribuindo para o aumento na qualidade de vida das famílias.

As famílias atendidas passaram a ter além de maior qualidade na alimentação, acesso a equipamentos eletrodomésticos e eletroeletrônicos que proporcionam um acréscimo na qualidade de vida das famílias. Isto ocorre, pois ao fazer parte do PBF a maioria destas pessoas passa a ter uma renda fixa mensal que pode ser comprovada. Antes isso não era possível, pois grande parte trabalha na informalidade. Garantida esta comprovação da renda as famílias têm acesso ao microcrédito, conforme apontamento, o que permite a aquisição, de forma parcelada, de equipamentos que melhoram o conforto e a qualidade de vida das famílias assistidas. Outro elemento identificado é que esta renda circula na região periférica da cidade, favorecendo pequenos comerciantes.

As principais críticas ao programa dizem respeito ao fato do mesmo não conseguir cumprir suas condicionalidades. Este estudo não verificou o seu cumprimento ou não. No entanto, do ponto de vista econômico, os resultados são positivos, haja vista que aumentou a propensão a consumir da sociedade brasileira e contribuiu para redução da desigualdade de renda entre as famílias.

A pesquisa desenvolvida é bastante peculiar por tratar especificamente da economia de Sinop-MT e poderá nortear novos estudos que ainda serão elaborados. Sabe-se que a discussão a cerca do PBF é objeto de estudos de grandes especialistas na área econômica, social e política. Portanto, o presente estudo pode ser aplicado pelo executivo municipal para o acompanhamento social e econômico das famílias carentes, norteando políticas setoriais que possam complementar os esforços do governo federal na busca por distribuição de renda de maneira equilibrada.

\section{Referências}

BLANCHARD, O. Macroeconomia. 2.ed. Rio de Janeiro: Campus, 2001.

BRASIL. Lei $N^{0} 10.836$, de 09 de Janeiro de 2004. Disponível em: <http://www.mds.gov.br/bolsafamilia/menu_ superior/legislacao_e_instrucoes/leis-1>. Acesso em: 22 ago. 2009.

CAIXA ECONOMICA FEDERAL. Benefícios Sociais. 2009. Disponível em: <https://www.beneficiossociais. caixa.gov.br/consulta/beneficio/04.01.00-00_00.asp>. Acesso em: 5 set. 2009.

CRUZ, M. J. V. da; PESSALI, H. F. As implicações da racionalidade limitada na elaboração de políticas compensatórias de combate à pobreza: uma análise do Programa Bolsa Família. Disponível em: <www.economia.ufpr.br/ publica/textos/2007/Cruz\%20e\%20Pessali-06062007. pdf>. Acesso em: 24 maio 2009.

FURTADO, C. Teoria e política do desenvolvimento econômico. 10.ed. Rio de Janeiro: Ed. Paz e Terra, 2000. 355 p.

GASTALDI, J. P. Elementos de Economia Política. 19.ed. São Paulo: Saraiva, 2005.

INSTITUTO BRASILEIRO DE GEOGRAFIA E ESTATÍSTICA - IBGE. Pesquisa Nacional por Amostra de Domicílio - PNAD, 2007. Disponível em: <http:/ / www. ibge.gov.br/cidadesat/topwindow.htm?1>. Acesso em: 22 set. 2009.

INSTITUTO DE PESQUISA ECONÔMICA APLICADA. Concentração da Renda no Brasil, 2008. Disponível em: <http://www.ipea.gov.br/default. jsp>. Acesso em: 12 set. 2009.

LAVINAS, L.; VARSANO, R. (Coord.). Programas de Garantia de Renda Mínima e Ação Coordenada de Combate a Pobreza. Texto para Discussão n. 534. Rio de Janeiro: Instituto de Pesquisa Econômica Aplicada - IPEA, 1997.

MEDEIROS, M.; BRITTO, T.; SOARES, F. Programas focalizados de transferência de renda no Brasil: Contribuições para o debate. Texto para Discussão. Brasília: Instituto de Pesquisa Econômica Aplicada - IPEA, junho de 2007.

MINISTÉRIO DO DESENVOLVIMENTO SOCIAL E COMBATE A FOME. Secretaria Nacional de Renda e Cidadania, 2009. Disponível em: <http:/ / www.mds.gov. br/bolsafamilia>. Acesso em: 10 set. 2009.

MINISTÉRIO DO TRABALHO E EMPREGO. Cadastro Geral de Empregados e Desempregados. Disponível em: $<$ http://estatistica.caged.gov.br/consulta>. Acesso em: 8 maio 2009.MUSGRAVE, R. A. Teoria das finanças públicas. São Paulo: Atlas, 1974.

SECRETÁRIA DE PLANEJAENTO E COORDENAÇÃO GERAL DO ESTADO DE MATO-GROSSO. Censo econômico de Sinop, 2007. Disponível em: <http:/ / www.indicador. seplan.mt.gov.br/censo/>. Acesso em: 22 ago. 2009.

SEN, A. Desenvolvimento como Liberdade. São Paulo: Companhia da Letras, 2000.

SOARES, D. S. D. O Ritmo de queda na desigualdade no Brasil é adequado? Evidências do contexto histórico e internacional. Texto para discussão n. 1339. Rio de Janeiro: Instituto de Pesquisa Econômica Aplicada - IPEA, 2005.

WEISSHEIMER, M. A. Bolsa família: avanços, limites e possibilidades do programa que está transformando a vida de milhões de famílias no Brasil. São Paulo: Editora Fundação Perseu Abramo, 2006. 